\title{
Comparison and evaluation of job selection dispatching rules for integrated scheduling of multi-load automatic guided vehicles serving in variable sized flexible manufacturing system layouts: A simulation study
}

\author{
S. Angra ${ }^{a}$, A. K. Chanda ${ }^{b}$ and V. K. Chawla ${ }^{a}$
}

${ }^{a}$ Department of Mechanical Engineering, National Institute of Technology, Kurukshetra, Haryana, India ${ }^{b}$ Department of Mechanical and Automation Engineering, G.B. Pant Engineering College, Delhi, India

\section{H R O N I C L E}

Article history:

Received: November 26, 2017

Received in revised format: January 31, 2018

Accepted: March 16, 2018

Available online:

March 16, 2018

Keywords:

AGVS

Dispatching Rules

FMS

Simulation

\section{A B S T R A C T}

This paper compares and evaluates the performance of five different conventional job selection dispatching rules for scheduling of multi-load automatic guided vehicles (AGVs) serving for material handling operations in variable sized flexible manufacturing system (FMS) layout. Four sizes of FMS layout are considered for the performance evaluation of the five types of conventional job selection dispatching rules. The FMS layouts under consideration are served by the two multi-load AGVs. The multi-load AGVs cruises under machine initiated the nearest vehicle (NV) dispatching rule for the material handling activities at all work centers (WCs) for all four sizes of FMS layout. Four sizes of FMS layout produce five different types of parts and consist of three, six, nine and twelve work centers and loading-unloading centers, respectively. In the simulation test, it is found that the identical destination first (IDF) job selection rule having selection criterion based on the destination similarity of two picked up jobs outperforms all other job selection dispatching rules for an overall production rate of the FMS (parts/hr) in all four FMS layouts.

\section{Introduction}

C) 2018 by the authors; licensee Growing Science, Canada

The dispatching and scheduling of multi-load AGVs for material handling activities along with manufacturing operations is one of the significant as well as complex tasks in the FMS. With the inception of AGVs in modern manufacturing systems, AGVs are found to yield more and more successful and efficient applications in the field of material handling activities for FMS. The application of AGVs in material handling operations has been increased tremendously (Hammond, 1986). The increase in the applications of AGVs in FMS always generated motivation for researchers to investigate various AGVrelated issues to optimize the material handling operations and maximize the sustainable production output and profit (Chawla et al., 2018d).

In an FMS different types of computer controlled work centers can work synchronously to machine different types of jobs which are supplied to work centers by the cruising AGVs in the FMS layout.

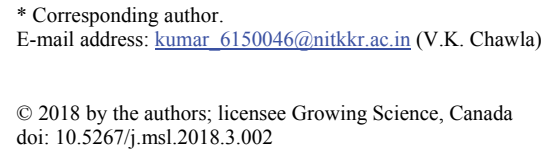


The AGVs of different capabilities are available for selection and application i.e. AGV can be unidirectional or bidirectional and it may have the unit load carrying capacity or multi-load carrying capability. Selection of appropriate AGVs type largely depends on the type of layout and production rate of FMS.

The jobs are machined on the machines under some set of dispatching rules known as job selection dispatching rules i.e. some measures are fixed to decide the priority of any job to be machined first or last by the work center out of several jobs available in the queue at a specific work center. The AGVs generally transfer or supply jobs under some different set of dispatching rules. The dispatching rules applied for material transfer by AGVs can be work center initiated or can be job initiated. The material transfer is carried out from a set of pick up points to a set of delivery points, the pickup or delivery points can be from the same group of units for example group of work centers in which the job machining is carried out in some random or sequential manner. The pickup and delivery points can also be from some other different groups for example machining group to painting/coating centers group or to packaging machines group. The material distribution is required at different work centers for different machining operations in any manufacturing unit.

In this paper, four sizes of FMS layout models are simulated for performance evaluation of five types of job selection dispatching rules. The FMS layouts constitute of three, six, nine and twelve types of work centers along with a loading-unloading center. Five different types of parts are produced in the aforesaid FMS configurations. The raw material in semi-finished or in finished form is transferred in between the work centers from and to the loading and unloading center. The material transfer action from one work center to another work center is performed by the multi-load AGVs cruising in the FMS. The job sequencing and operations on the job are performed by the work center according to job selection dispatching rule. Further, the AGV operates, transfer materials within the FMS layout under machine initiated dispatching rule i.e. according to predefined route and schedule as initiated by the work centers. The dispatching rules for the multi-load AGVs movement and for jobs being machined on the WCs are different. Efficiency, throughput, and makespan of jobs being produced in entire FMS are dependent on selection and application of appropriate dispatching rules. Performance evaluation of five conventional job selection dispatching rules for scheduling of multi-load AGVs cruising in variable sized FMS layout is performed by conducting a simulation experiment. The four different sizes of FMS model were simulated and job selection dispatching rules were applied to all the models under some performance criteria.

There are 4 more sections in this paper, in section 2 literature reviews is discussed, in section 3 simulation methodologies, parameters and all four FMS layouts are presented, simulation results are presented in section 4 and in section 5 the paper is concluded along with possible future directions of research.

\section{Literature Review}

The AGVs are generally used for job transfers in FMS or for material transfers at the ports. Application of AGVs in FMS increases the throughput of FMS and lowers the makespan of part production. Selection and application of appropriate $\mathrm{AGV}$ route and schedule between the pickup and delivery points play a vital role in achieving optimum utilization of AGVs for material handling operations serving in the FMS (Cheng, 1987; Hao et al., 1996; Guzman et al., 1997). In order to achieve smooth and efficient material handling operations, it is imperative to avoid any conflict or deadlock between the AGVs. Appropriate consideration on the probability of deadlock situation should be given while selecting the route for the material transfer and also while performing the work assignment to the AGVs and work centers (Kim \& Tanchoco, 1991; Langevin et al., 1996; Lin et al., 2006). Hence, scheduling and routing of AGVs largely depend on each other. The integrated scheduling of AGVs and FMS is a complicated and challenging assignment in real time automated production systems in which a high dynamic control 
on production resources is required (Taghaboni \& Tanchoco, 1995; Rajotia et al., 1998). AGV dispatching rules in the FMS are generally based on a push or pull concept as found by Yim and Linnt (1993). A Petri-net-based simulation study was used by Yim and Linnt (1993) to find out the effect of vivid dispatching rules on the performance parameters of the FMS. An alternate control strategy for multi-load AGVs was introduced by the Tanchoco and Co (1994) in which the multi-load AGVs were allowed to deviate from their original route so as to enable them to pick up additional loads and can carry loads with different destinations simultaneously on board. Tanchoco and Co (1994); Bilge and Tanchoco (1997) demonstrated the potential benefits of using multi-load AGVs and implemented control strategies considering issues like network congestion and guide path design. Further authors analyzed and compared the robustness and degree of flexibility offered by multi-load AGVs in comparison to the unit-load AGV systems. Lee et al. (1996) studied the effects of load-selection issues on the performance of multi-load AGVs in the FMS. Performance of multi-load AGVs under different guide path configurations and under vivid AGV control strategies was investigated by Ho and Shaw (2000) and author's experimental results clearly showed that a rule's performance is affected by the design of flow path configurations. Ho and Liu (2009) introduced a control process for multi-load AGVs and their control process investigated three main issues that a multi-load AGV may go through those were i) task-determination issue, ii) delivery-dispatching issue and iii) load selection issue. Authors investigated task-determination problem and delivery-dispatching problem together and proposed different dispatching rules for them on the basis of results obtained from simulation of proposed rules. Ho and Liu (2009) also investigated the load-selection issues and proposed various load-selection rules after conducting simulation and analysis of load selection rules. Um et al. (2009) applied combined simulation-based analytic and optimization technique and named it as multi-objective non-linear programming (MONLP) and evolution strategy (ES) to minimize the AGV utilization, congestion and maximize the throughput of the FMS. Performance criteria such as system throughput (ST), mean flow time of parts (MFTP), mean tardiness of parts (MFTP) and AGV idle time (AGVIT) etc. were considered by Azimi et al. (2010) to rank various control strategies by applying a TOPSIS method. Ho et al. (2012) investigated multiple attribute method to analyze pick up-dispatching and the load selection problems simultaneously for multi-load AGVs. Sadrabadi and Sadjadi (2009) solved multi-objective problems by application of a newly proposed interactive algorithm. The algorithm found to initiate and search solutions from the infeasible area to the feasible area. The proposed algorithm observed to handle its nonlinear utility effectively. Moghadam et al. (2010) solved vehicle routing issues under uncertain demands. Authors applied a robust optimization and carried out computational experiments to find the effect of the deterministic solution, the robust and the trade-offs. Further, the authors validated their approach by applying it to the medicine distribution case study and found their approach to decrease uncertain demands drastically. Moghadam et al. (2012) solved uncertain vehicle routing problem by application of an advanced particle swarm optimization algorithm. Authors compared and validated the yield of results from the applied algorithm with another existing algorithm. Bozorgi-Amiri et al. (2015) applied a memetic algorithm to minimize the travel path of a vehicle by solving a split delivery vehicle routing problem. Authors focused on energy consumed and the load carried by the vehicle. Bottani et al. (2017) applied a modified discrete firefly algorithm to solve work center loading problem in the FMS. Wang et al. (2016) introduced tardiness estimating method (TEM) by applying new part launching dispatching rule and further analyze random arrival of jobs in a dynamic FMS. Wang et al. (2016) conducted discrete-event simulation experiment under varying system operating environment. Authors found that the proposed TEM performs satisfactorily for minimum mean tardiness, maximum service level and yield moderate flow time in comparison to other dispatching rules. Chawla et al. (2018 a) applied an evolutionary MMPSO algorithm for scheduling of multi-load AGVs in the FMS. Chawla et al. (2018 b) compared the results yield for optimization of AGV fleet size by application of grey wolf optimization (GWO) algorithm and analytical model. The resulting yield of GWO observed to be better than the results of the analytical model. An analytical model for the solution of loading and unloading problem in FMS with minimum computational time in the FMS was proposed by Singh \& Khan (2016). Chawla et al. (2018 d) applied artificial immune system for the solution of the multi-objective simultaneous scheduling problems of AGVs in the FMS. 
From the above-cited literature, it is clear that routing and scheduling of AGVs are performed under a set of dispatching rules which clearly shows that appropriate selection of dispatching rules will increase FMS material handling operations efficiency, throughput and lower down tardiness along with makespan of jobs. Moreover, selection of appropriate dispatching rule reduces complexity in routing and scheduling of multi-load AGVs in the FMS. The literature review also identifies a potential research gap to compare and evaluate the job selection dispatching rules for integrated scheduling of multi-load AGVs to carry out real-time material handling operations in the variable sized FMS layouts. In the present paper, an attempt is carried out to fill aforesaid research gap by conducting the discrete event simulation experiment by using Arena.

\section{Problem Statement and Simulation Model}

The literature review clearly shows need to address the comparison and performance evaluation of job selection dispatching rules for differently sized FMS layouts so that appropriate dispatching rule can be selected for integrated scheduling of multi-load AGVs to carry out the real-time material handling operations efficiently in the differently sized FMS layouts. Dispatching rules can be of two types namely static and dynamic. With the change in time job priority values remains constant in static dispatching rules and the values are not dependent on time. There can be three basic parameters for a static dispatching rule.

i. Machining time: Time elapsed to produce part "a" on a single work center "b".

ii. Machining sequence: Total number of machining sequence required for the production of part "a" to complete the production process.

iii. Total machining time: Total machining time elapsed for production of part "a" to complete the production process on all the work centers in the FMS.

Contrary to dynamic dispatching rules the job priority values changes with a change in time and are dependent on the time, there can be three basic parameters for a dynamic dispatching rule.

i. Creation time: The time when a part "a" is created.

ii. Waiting time: The time that part "a" spent while waiting in queue on a single work center "b".

iii. Total work remaining: Total work remaining for completion of part "a" to complete all machining operations on all work centers in the FMS.

In this paper, five conventional job-selection dynamic dispatching rules are applied between jobs and work center operating in four different sizes of the FMS. The four sizes of FMS layout consist of three, six, nine and twelve work centers and loading-unloading center respectively and in all four FMS layout, five different types of parts are produced. In the all four FMS layouts, "P" is the pickup point of the material and " $\mathrm{D}$ " is drop off point for the material that a multi-load AGV can use for material handling operations in the entire FMS layout. From the literature review, it is observed that a very few research is carried out on the performance evaluation of job selection dispatching rules for multi-load AGVs operating in different sizes of FMS layouts under different performance criteria. The four different FMS layouts for simulation are shown in Figs. (1-4).

Following simulation parameters were applied to carry out the simulation test in the Arena simulation software with following experimental conditions: (Kelton, 2002).

i. Minimum run length of simulation for one type of FMS: $1500 \mathrm{~min}$.

ii. Transient phase in one type of FMS: $700 \mathrm{~min}$.

iii. Total no. of experimental runs for one type of FMS: 4

iv. Total run time for one type of FMS: $700+(4 \mathrm{X} \mathrm{1500)}=6700 \mathrm{~min}$.

v. Total run time for all four types of FMS: $6700 \times 4=26800 \mathrm{~min}$. 
vi. AGVs velocity variation: $30 \mathrm{~m} / \mathrm{hr} ; 60 \mathrm{~m} / \mathrm{hr} ; 90 \mathrm{~m} / \mathrm{hr} ; 120 \mathrm{~m} / \mathrm{hr} ; 150 \mathrm{~m} / \mathrm{hr}$.

vii. Number of AGVs: 2.

viii. Simulation software used: Arena.

Following assumptions are taken before simulating the FMS including AGVs.

i. AGVs and work centers are $100 \%$ reliable and are always prepared for the task assignment.

ii. One machining operation can be performed on a work center at a time.

iii. Operation times are deterministic in nature.

iv. There is no rework or scrap generation on jobs.

v. The part type mix and release are known.

vi. No congestion and no deadlock are observed in multi-load AGVs in the FMS layout.

vii. Time spent to load and unload jobs is negligible.

viii. The multi-load AGVs operates under WC initiated the nearest vehicle first (NV) dispatching rule for material handling activities in all four types of the FMS.

The FMS layouts under consideration as shown in Fig. 1, Fig. 2, Fig. 3 and Fig. 4 are portioned type in which two multi-load AGVs cruises on the guide path laid in the FMS layouts. Apart from two multiload AGVs, the FMS layouts constitute of three, six, nine and twelve WCs having individual pick-up (P) and drop-off(D) point in addition to WCs all the FMS layouts also consists of loading and unloading center which stores the raw material, semi-finished and finished parts according to requirement. The multi-load AGVs load and unload material to and from loading unloading center and further to various work centers. The represented layouts are simpler and can be widely put in an application for real-time manufacturing operations or for production of parts in automobile ancillaries, tool rooms, and defense facility. The layouts being simple in design found to be the best fit for small to medium scale FMS which further leads to easy and efficient real-time application of multi-load AGVs for the material handling operations.

Fig. 1 shows FMS layout with one loading and unloading center and three work centers which are namely horizontal milling center (HMC), vertical milling center (VMC) and coordinate measuring machine center (CMM).



Fig. 1. FMS layout 1

Fig. 2 represents FMS layout with one loading and unloading center and six work centers namely horizontal milling center (HMC), vertical milling center (VMC), de-burring center, welding center, painting, and coating center and coordinate measuring machine center (CMM) respectively. 
Table 1

Part type routing and manufacturing characteristics for the FMS layout 1

\begin{tabular}{cccc}
\hline Part type & Operation number & Work-station & Processing time (min) \\
\hline \multirow{2}{*}{1} & 1 & 1 & 11 \\
& 2 & 3 & 16 \\
2 & 1 & 2 & 10 \\
& 2 & 1 & 14 \\
& 3 & 2 & 17 \\
\multirow{2}{*}{3} & 4 & 3 & 12 \\
& 1 & 1 & 16 \\
& 2 & 2 & 13 \\
\hline \multirow{2}{*}{4} & 3 & 3 & 9 \\
& 1 & 2 & 14 \\
& 2 & 1 & 12 \\
\multirow{2}{*}{5} & 3 & 2 & 14 \\
& 4 & 3 & 11 \\
\hline
\end{tabular}

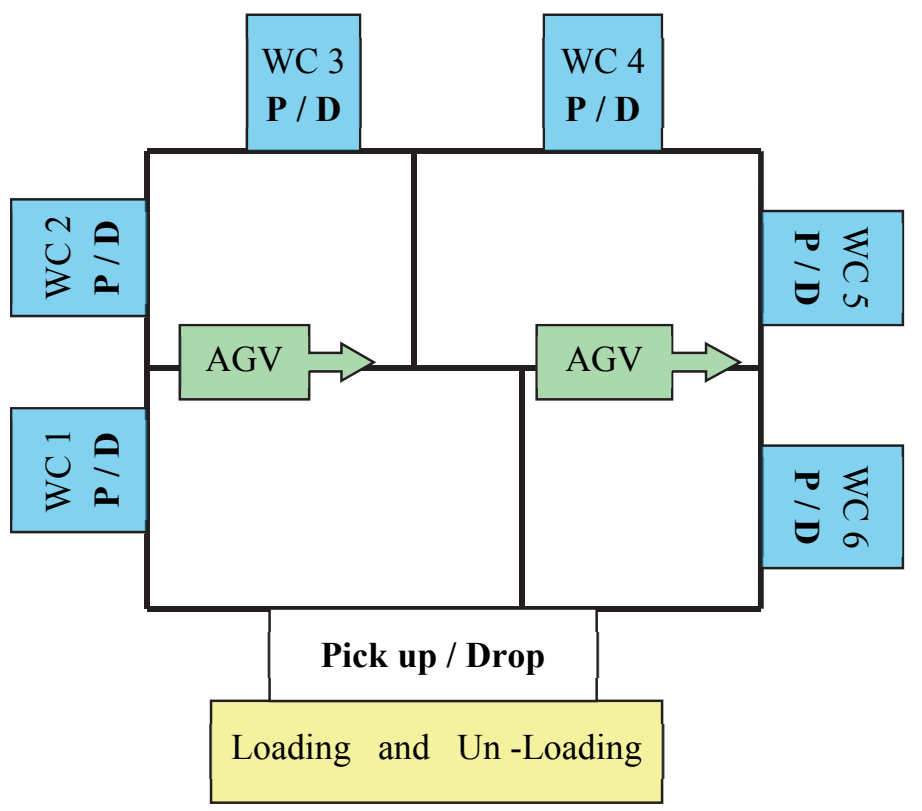

Table 2

Fig. 2. FMS layout 2

Part type routing and manufacturing characteristics for the FMS layout 2

\begin{tabular}{|c|c|c|c|}
\hline Part type & Operation number & Work-station & Processing time (min) \\
\hline \multirow[t]{2}{*}{1} & 1 & 1 & 9 \\
\hline & 2 & 6 & 16 \\
\hline \multirow{4}{*}{2} & 1 & 2 & 10 \\
\hline & 2 & 3 & 11 \\
\hline & 3 & 5 & 13 \\
\hline & 4 & 6 & 12 \\
\hline \multirow{3}{*}{3} & 1 & 4 & 12 \\
\hline & 2 & 3 & 15 \\
\hline & 3 & 6 & 13 \\
\hline \multirow{4}{*}{4} & $\frac{1}{4}$ & 4 & 7 \\
\hline & 2 & 2 & 12 \\
\hline & 3 & 3 & 8 \\
\hline & 4 & 6 & 14 \\
\hline \multirow{3}{*}{5} & 1 & 2 & 10 \\
\hline & 2 & 4 & 13 \\
\hline & 3 & 6 & 15 \\
\hline
\end{tabular}


Fig. 3 constitutes of FMS layout with one loading and unloading center and nine work centers namely two horizontal milling center (HMC), two vertical milling center (VMC), one de-burring center, two welding centers, one painting and coating center and one coordinate measuring machine center (CMM) respectively.

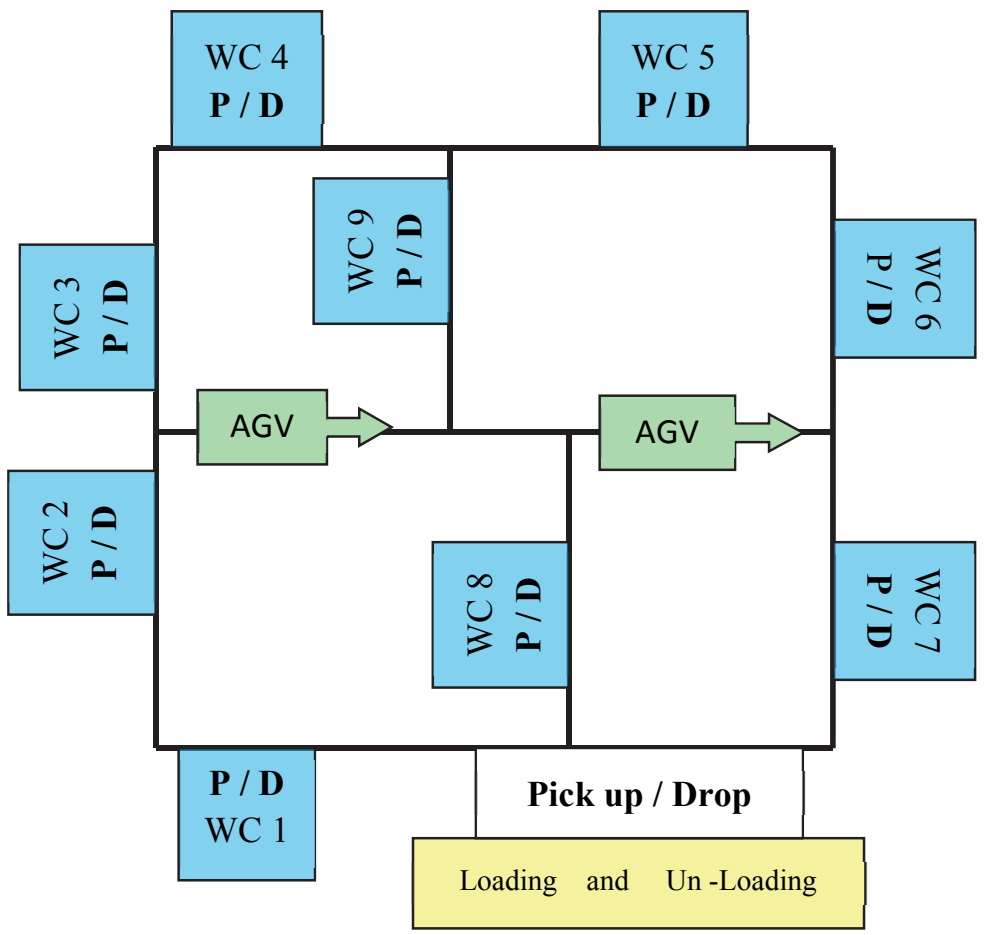

Fig. 3. FMS layout 3

In Fig. 4, FMS layout appears with two loading and unloading center and twelve work centers namely three horizontal milling center (HMC), three vertical milling center (VMC), two de-burring centers, two welding center, one painting, and coating center and one coordinate measuring machine center (CMM) respectively.

Table 3

Part type routing and manufacturing characteristics for the FMS layout 3

\begin{tabular}{cccc}
\hline Part type & Operation number & Work-station & Processing time (min) \\
\hline \multirow{2}{*}{1} & 1 & 3 & 8 \\
& 2 & 9 & 16 \\
\hline \multirow{2}{*}{2} & 1 & 4 & 9 \\
& 2 & 7 & 12 \\
\hline \multirow{2}{*}{3} & 3 & 6 & 12 \\
& 4 & 9 & 9 \\
& 1 & 5 & 12 \\
& 2 & 2 & 13 \\
& 3 & 9 & 7 \\
& 1 & 1 & 8 \\
& 2 & 3 & 12 \\
& 3 & 7 & 14 \\
\hline \multirow{2}{*}{5} & 4 & 9 & 13 \\
& 1 & 1 & 11 \\
\end{tabular}




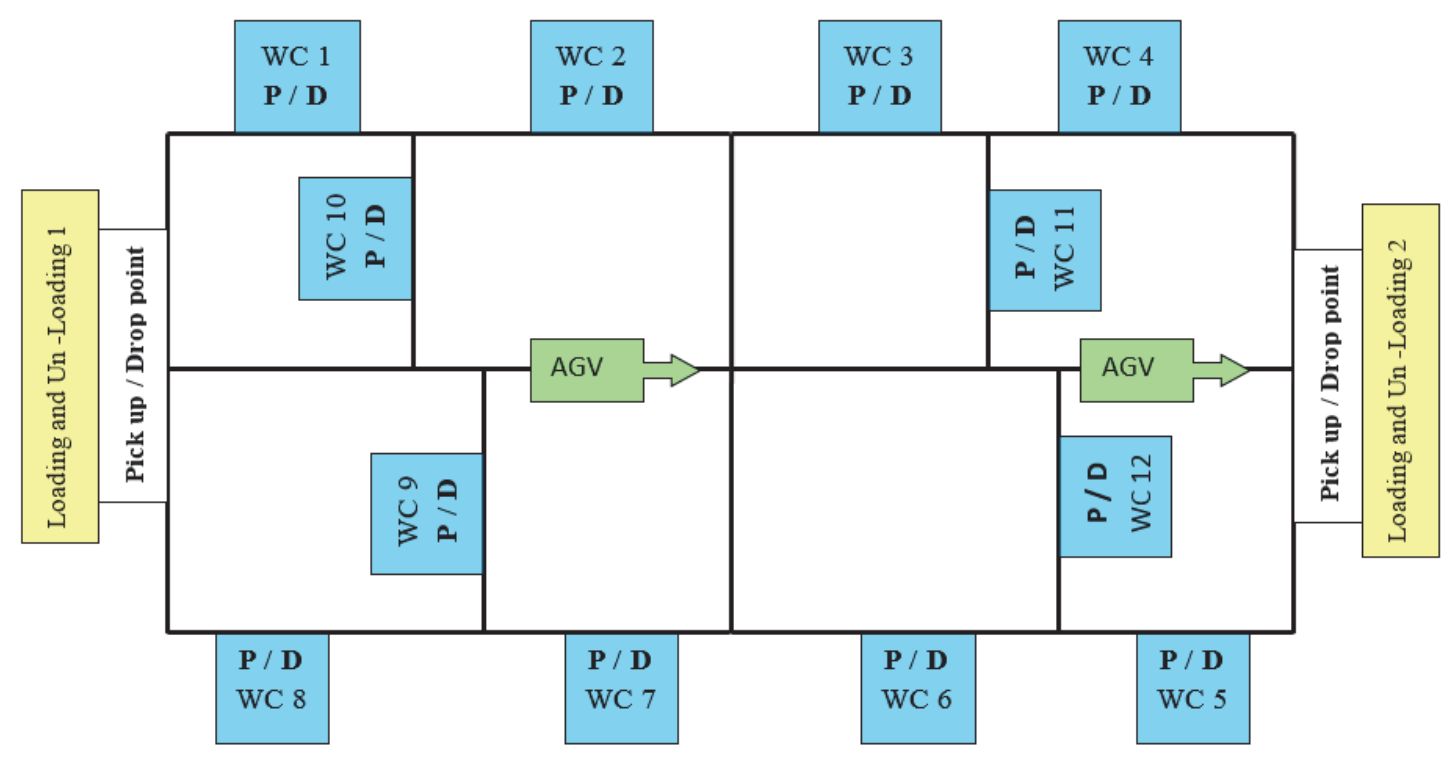

Fig. 4. FMS layout 4

All work centers in all four FMS layouts exhibits varying operational capabilities. The part type mix ratio and machining operation sequence are known and predefined. The part type mix ratio is assumed to be one and different part types are dispatched alternately to all FMS layouts for different manufacturing operations or processes. Production of five types of parts can be done in aforesaid FMS layouts. The operation sequence and routing sequence for parts 1, 2, 3, 4 and 5 are mentioned in Table 1, 2, 3 and 4 for FMS layouts represented in Figs. (1-4), respectively.

\section{Table 4}

Part type routing \& manufacturing characteristics for the FMS layout 4

\begin{tabular}{cccc}
\hline Part type & Operation number & Work-station & Processing time (min) \\
\hline 1 & 1 & 3 & 8 \\
& 2 & 12 & 16 \\
2 & 1 & 1 & 12 \\
& 2 & 4 & 7 \\
& 3 & 7 & 12 \\
\hline \multirow{2}{*}{3} & 4 & 12 & 9 \\
& 1 & 6 & 10 \\
& 2 & 5 & 13 \\
\hline \multirow{2}{*}{4} & 3 & 12 & 8 \\
& 1 & 2 & 11 \\
& 2 & 8 & 9 \\
\hline \multirow{2}{*}{5} & 3 & 3 & 14 \\
& 4 & 12 & 10 \\
& 1 & 1 & 12 \\
\hline
\end{tabular}




\section{Start}

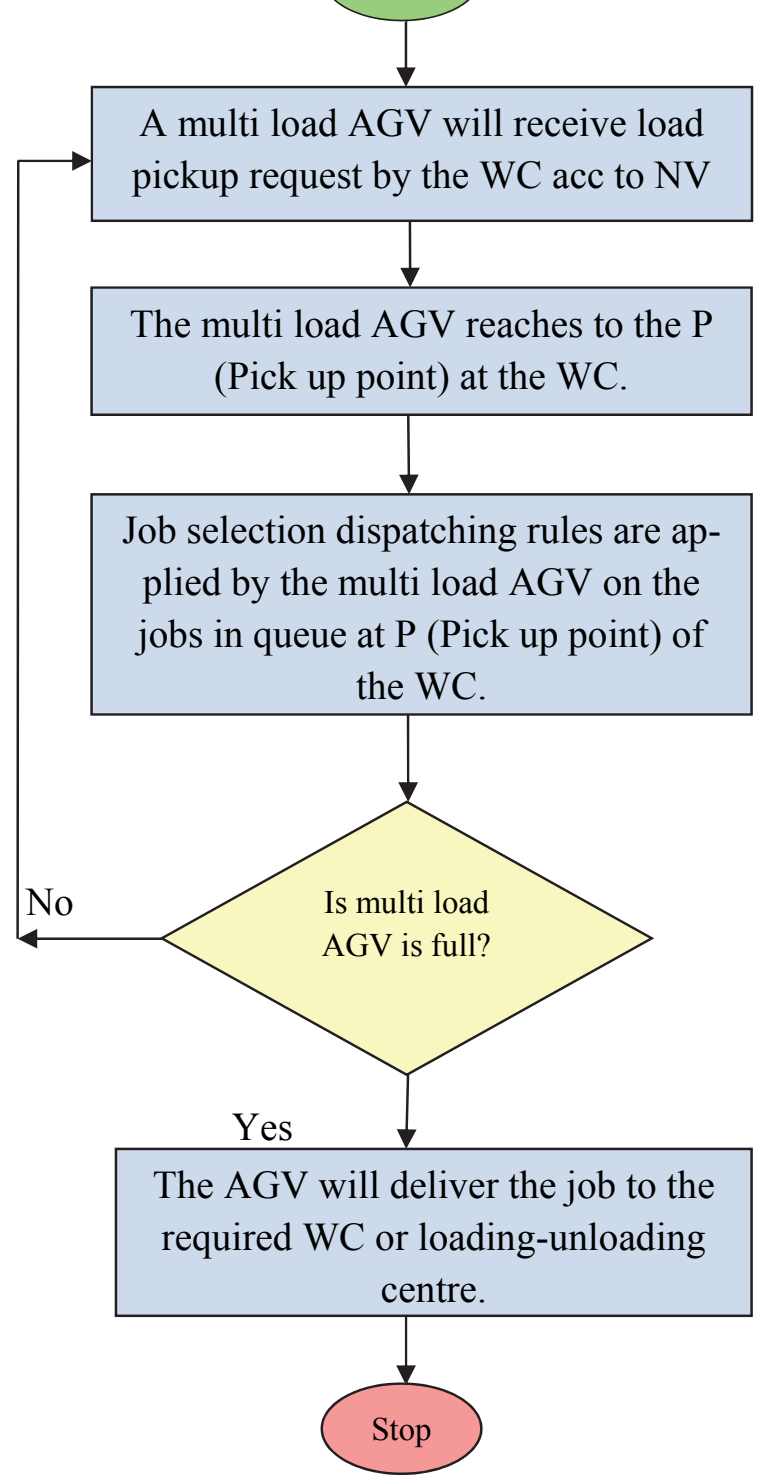

Fig. 5. Process flowchart

In the simulation test of all four FMS layouts following five job selection dynamic dispatching rules were applied and then evaluated which are as follows:

1. Smallest Remaining Processing Time First (SRPTF)

In SRPTF rule a multi-load AGV pickups the job having smallest remaining processing time from pick up point "P".

2. Smallest Slack Time First (SSTF)

In SSTF rule the multi-load AGV pickups the job having smallest slack time from the pickup point "P".

3. Identical Destination First (IDF)

The IDF rule works on the similarity between the destinations points of various jobs. On application of the IDF rule, the load with next destination identical to the next destination of any other job loaded on the multiple-load AGV will be picked up first. The IDF rule will work as follows: 
i) From pick up point "P", identify the job having next destination is identical to the next destination of any job already on multi-load AGV. If no job is identified, then from "P" identify the job having longest waiting time in the queue of "P".

ii) Let "J" stand for the job identified above then Multi-load AGV V picks up the job "J" first.

4. Longest Time in the System First (LTSF)

In LTSF rule the multi-load AGV will pick up the job from pick up point "P" having the greatest time in the system.

5. Greatest Waiting Time in Queue First (GWTQF).

According to GWTQF rule, the multi-load AGV will pick up the job having the greatest waiting time in the queue from the pickup point "P".

The following performance criteria were used to compare and evaluate the relative performance of job selection dynamic dispatching rules.

1) Overall Production Rate of the FMS (parts/hr).

2) Mean Work Centre Utilization (\%).

3) Mean AGV Utilization in the FMS (\%).

\section{Simulation results}

The simulation experiments for the analysis and evaluation of job selection dynamic dispatching rules with two multi-load AGVs operating in four FMS layouts is performed. The multi-load AGV speed was varied with the same magnitude in all four FMS layouts. The multi-load AGVs operated on five speeds as $30 \mathrm{~m} / \mathrm{hr} ; 60 \mathrm{~m} / \mathrm{hr} ; 90 \mathrm{~m} / \mathrm{hr} ; 120 \mathrm{~m} / \mathrm{hr} ; 150 \mathrm{~m} / \mathrm{hr}$. The simulation results for all four FMS layouts achieved from the ARENA software are tabulated in Table 5 and the results are plotted in form of graph in Fig. 6, Fig. 7 and Fig. 8 representing overall production rate of FMS, mean AGV utilization $(\%)$ and mean work centre utilization (\%) for FMS layout 1.

Similarly Fig. 9, Fig. 10 and Fig. 11 represents plots for FMS layout 2, Fig. 12, Fig. 13 and Fig. 14 shows plots for FMS layout 3 and Fig. 15, Fig. 16 and Fig. 17 represents plots for overall production rate of FMS, mean AGV utilization (\%) and mean work center utilization (\%) for FMS layout 4.

Results in Table 5 and Fig. 6 to Fig. 14 for the FMS layout 1, 2 and 3 clearly indicates that the identical destination first (IDF) job selection rule having a selection criterion based on the destination similarity of two picked up jobs outperforms all other job selection dispatching rules for different AGV velocities. Fig. 15 and Fig. 16 also shows that IDF job selection rule performs better than all other dispatching rules for overall production rate and mean work center utilization in FMS layout 4, however in Fig. 17 the performance of IDF rule for mean AGV utilization in FMS layout 4 found to be at par with other selection rules. This may because of the size of FMS layout 4. The FMS layout 4 consists of 12 WC and 2 loading-unloading centers which are located far from each other. So due to large distance between WC and loading-unloading center the AGV and at speed of $30 \mathrm{~m} / \mathrm{hr} ; 60 \mathrm{~m} / \mathrm{hr} ; 90 \mathrm{~m} / \mathrm{hr} \mathrm{dispatching}$ rule does not perform as good as it performs in FMS layout 1, 2 and 3, however the performance of AGV increases at speed of $120 \mathrm{~m} / \mathrm{hr}$ and at speed of $150 \mathrm{~m} / \mathrm{hr}$ it becomes constant in FMS layout 4 . This can be a reason for the declination of the performance of IDF rule in FMS layout 4. However, the performance of IDF rule for overall production rate and for mean work center utilization in FMS layout 4 is better than all other job selection dispatching rules as the FMS layout 4 consist of more number of WC. The performance in terms of mean AGV utilization might increase with an increase in the number of AGVs. The greatest waiting time in queue first (GWTQF) job selection dispatching rule in which the multi-load AGV picks up job with greatest waiting time in queue at the WC of the FMS found to have the least performance for overall production rate, mean work center utilization and mean AGV utilization in all four layouts of the FMS. The smallest remaining processing time first (SRPTF) and smallest slack time first (SSTF) job selection dispatching rule found to have moderate performance among all 
five types of job selection dispatching rules for overall production rate, mean work center utilization and mean AGV utilization in all four layouts of the FMS.

Results tabulated in Table 5 also show that the performance of FMS is not independent of AGV speed and number of AGVs. From tabulated results and plots represented from Fig. 6 to Fig. 14 for FMS layout 1, 2 and 3 it is crystal clear that with an increase of AGV speed the difference in performance of job selection dispatching rules decreases. However, at AGV speed of $120 \mathrm{~m} / \mathrm{hr}$, the performance of all dispatching rules becomes better in FMS layout 4. From the plots, it is also evident that at a certain AGV speed and after it the performance of all dispatching rules becomes constant. It may be due to the cause that at very high cruising speeds of multi-load AGVs, time spent in the movement of the job becomes insignificant and then application of job selection dispatching rules also found to be insignificant. Hence the performance of FMS depends on the speed of AGVs, selection of appropriate dispatching rule and optimum number of AGVs in the FMS layout.

Table 5

Simulation results of the layout 1 , layout 2 , layout 3 \& layout 4

\begin{tabular}{|c|c|c|c|c|c|c|c|c|c|c|}
\hline $\begin{array}{l}\text { AGV } \\
\text { speed }\end{array}$ & SRPTF & SSTF & IDF & LTSF & GWTQF & SRPTF & SSTF & IDF & LTSF & GWTQF \\
\hline $\mathbf{m} / \mathbf{h r}$ & \multicolumn{5}{|c|}{ FMS layout 1} & \multicolumn{5}{|c|}{ FMS layout 2} \\
\hline \multicolumn{11}{|c|}{ Overall production rate of the FMS (parts/hr) } \\
\hline 30 & 9.3 & 9.6 & 9.8 & 8.8 & 8.3 & 10 & 10.2 & 10.6 & 9.6 & 9.3 \\
\hline 60 & 12.1 & 12.7 & 14.4 & 11.9 & 11.6 & 12.6 & 13.3 & 15 & 12.4 & 12.1 \\
\hline 90 & 13.3 & 13.8 & 15.8 & 12.3 & 11.9 & 14 & 14.6 & 16.9 & 12.9 & 12.7 \\
\hline 120 & 11.0 & 11.0 & 11.0 & 11.0 & 11.0 & 11.8 & 11.8 & 11.8 & 11.8 & 11.8 \\
\hline 150 & 11.0 & 11.0 & 11.0 & 11.0 & 11.0 & 11.8 & 11.8 & 11.8 & 11.8 & 11.8 \\
\hline \multicolumn{11}{|c|}{ Mean work center utilization (\%) } \\
\hline 30 & 69.5 & 72.4 & 75.3 & 68.6 & 67.2 & 73.3 & 75.2 & 77.4 & 71.7 & 69.8 \\
\hline 60 & 76.5 & 77.2 & 80.3 & 73.4 & 72.9 & 77.4 & 78.5 & 81.1 & 75.6 & 73.4 \\
\hline 90 & 79.5 & 81.6 & 82.3 & 77.2 & 75.5 & 80.2 & 82.5 & 84.3 & 78.3 & 76.6 \\
\hline 120 & 76.6 & 76.6 & 76.6 & 76.6 & 76.6 & 77.3 & 77.3 & 77.3 & 77.3 & 77.3 \\
\hline 150 & 76.6 & 76.6 & 76.6 & 76.6 & 76.6 & 77.3 & 77.3 & 77.3 & 77.3 & 77.3 \\
\hline \multicolumn{11}{|c|}{ Mean AGV utilization in the FMS (\%) } \\
\hline 30 & 50.2 & 48.4 & 45.2 & 52.3 & 55.7 & 48.3 & 46.1 & 44.2 & 49.6 & 52.3 \\
\hline 60 & 48.3 & 44.2 & 40.2 & 51.1 & 53.2 & 46.1 & 43.3 & 39.8 & 48.8 & 51.5 \\
\hline 90 & 44.41 & 41.71 & 36.7 & 47.7 & 50.3 & 43.2 & 40.6 & 35.2 & 45.6 & 48.3 \\
\hline 120 & 22.7 & 22.7 & 22.7 & 22.7 & 22.7 & 21.6 & 21.6 & 21.6 & 21.6 & 21.6 \\
\hline 150 & 22.7 & 22.7 & 22.7 & 22.7 & 22.7 & 21.6 & 21.6 & 21.6 & 21.6 & 21.6 \\
\hline \multicolumn{6}{|c|}{ FMS layout 3} & \multicolumn{5}{|c|}{ FMS layout 4} \\
\hline \multicolumn{11}{|c|}{ Overall production rate of the FMS (parts/hr) } \\
\hline 30 & 10.2 & 11.1 & 11.5 & 9.6 & 8.9 & 9.7 & 10.0 & 10.5 & 9.3 & 9.0 \\
\hline 60 & 13.9 & 15.2 & 16.6 & 13.2 & 12.7 & 12.2 & 13.1 & 14.8 & 12.0 & 11.5 \\
\hline 90 & 14.6 & 16.1 & 18.6 & 13.8 & 13.0 & 13.6 & 14.1 & 16.4 & 12.4 & 12.2 \\
\hline 120 & 12.8 & 12.8 & 12.8 & 12.8 & 12.8 & 16.3 & 17.6 & 19.1 & 15.2 & 14.4 \\
\hline 150 & 12.8 & 12.8 & 12.8 & 12.8 & 12.8 & 13.5 & 13.5 & 13.5 & 13.5 & 13.5 \\
\hline \multicolumn{11}{|c|}{ Mean work center utilization (\%) } \\
\hline 30 & 72.0 & 74.3 & 76.1 & 70.3 & 68.6 & 64.1 & 67.5 & 68.1 & 62.9 & 60.8 \\
\hline 60 & 76.1 & 77.3 & 80.2 & 74.1 & 72.2 & 68.3 & 69.3 & 70.2 & 66.7 & 65.6 \\
\hline 90 & 79.1 & 81.3 & 83.1 & 77.2 & 74.9 & 69.6 & 70.7 & 72.2 & 67.4 & 66.1 \\
\hline 120 & 76.3 & 76.3 & 76.3 & 76.3 & 76.3 & 70.8 & 71.4 & 73.5 & 69.5 & 68.3 \\
\hline 150 & 76.3 & 76.3 & 76.3 & 76.3 & 76.3 & 69.4 & 69.4 & 69.4 & 69.4 & 69.4 \\
\hline \multicolumn{11}{|c|}{ Mean AGV utilization in the FMS (\%) } \\
\hline 30 & 45.3 & 44.5 & 43.6 & 46.7 & 47.4 & 55.6 & 53.4 & 51.2 & 56.8 & 58.3 \\
\hline 60 & 41.3 & 39.8 & 38.6 & 43.7 & 45.8 & 46.1 & 47.3 & 48.6 & 45.3 & 44.5 \\
\hline 90 & 37.4 & 36.3 & 34.2 & 38.8 & 40.3 & 40.2 & 42.8 & 44.3 & 38.1 & 37.8 \\
\hline 120 & 20.8 & 20.8 & 20.8 & 20.8 & 20.8 & 41.7 & 40.6 & 38.3 & 42.6 & 43.7 \\
\hline 150 & 20.8 & 20.8 & 20.8 & 20.8 & 20.8 & 20.1 & 20.1 & 20.1 & 20.1 & 20.1 \\
\hline
\end{tabular}






Fig. 6. Production rate of layout 1

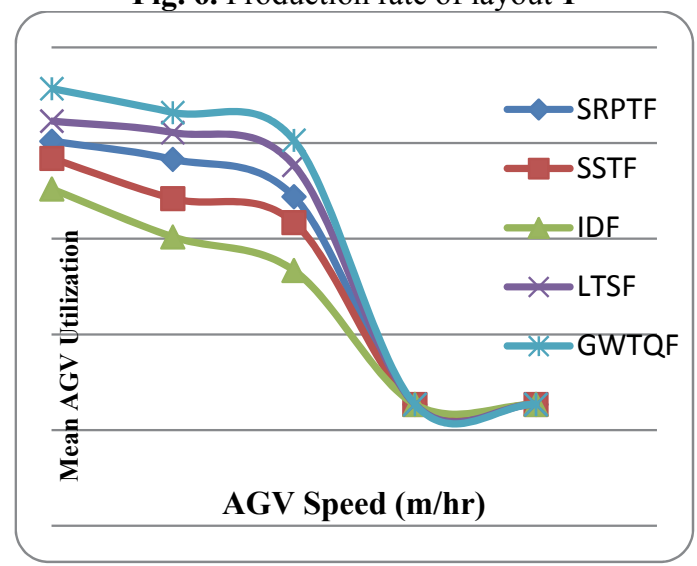

Fig. 8. Mean AGV utilization of layout 1

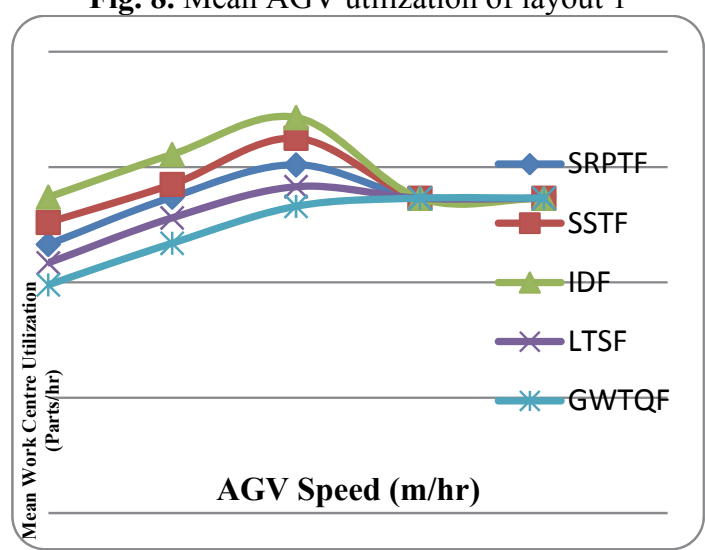

Fig. 10. Mean WC utilization of layout 2

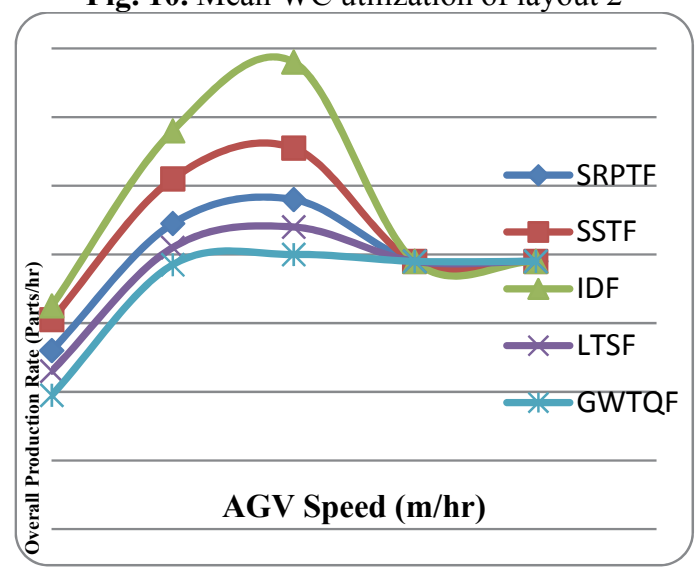

Fig. 12. Production rate of layout 3

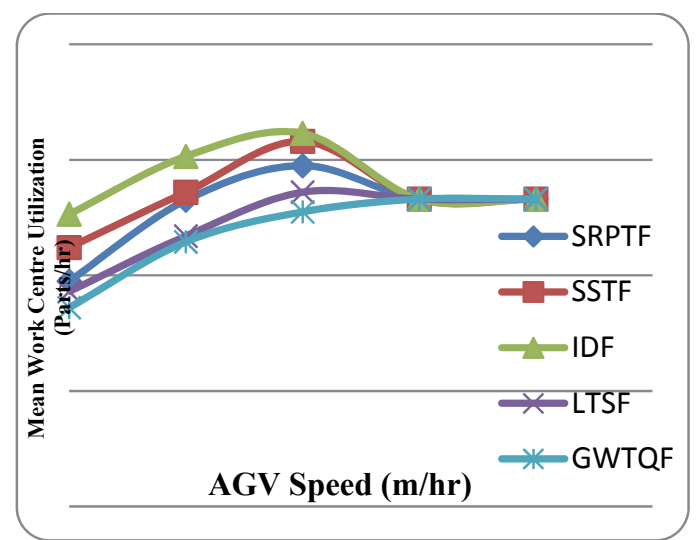

Fig. 7. Mean WC utilization of layout 1

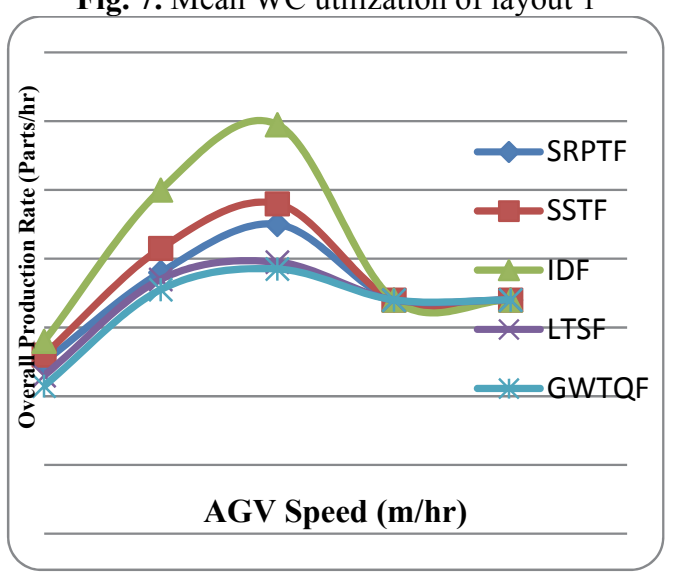

Fig. 9. Production rate of layout 2

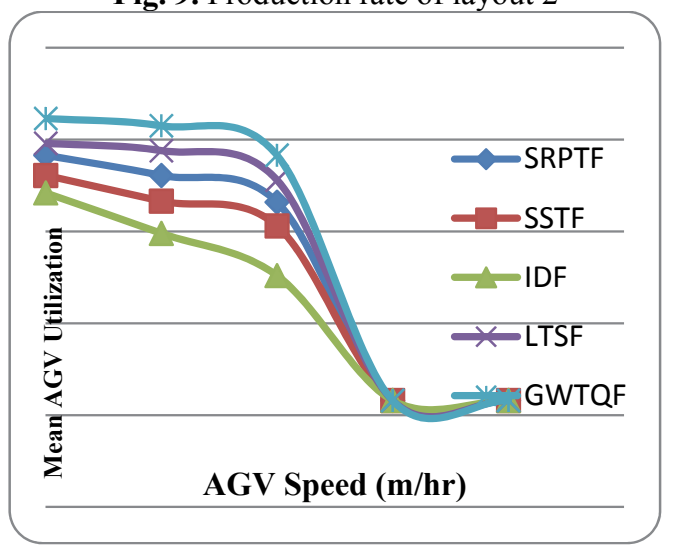

Fig. 11. Mean AGV utilization of layout 2

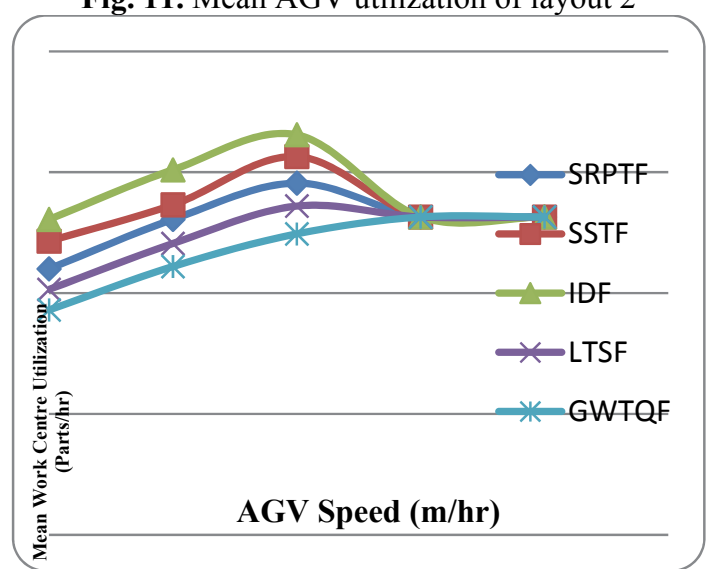

Fig. 13. Mean WC utilization of layout 3 


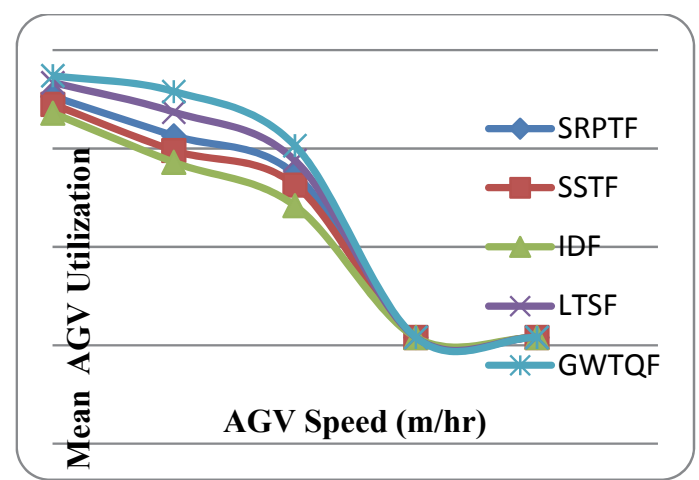

Fig. 14. Mean AGV utilization of layout 3



Fig. 16. Mean WC utilization of layout 4



Fig. 15. Production rate of layout 4

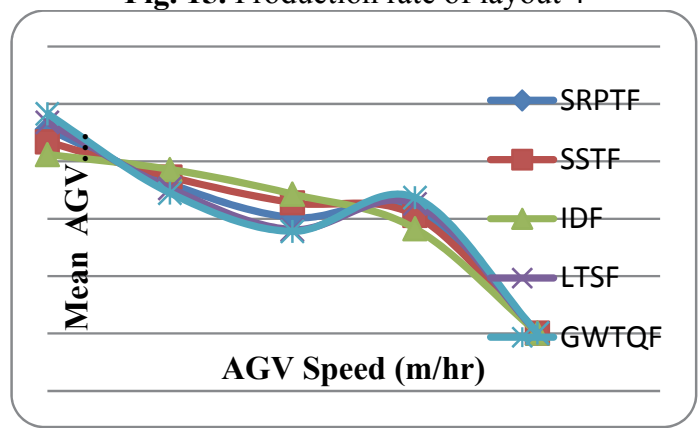

Fig. 17. Mean AGV utilization of layout 4

\section{Conclusion and future work}

In this paper comparison for performance evaluation of five job selection dispatching rules have been investigated by simulation experiments. Four sizes of FMS layout were modeled and simulated using ARENA simulation software. The sizes of FMS were varied in terms of number of WC consisted by the FMS. In simulation results, it was found that the identical destination first (IDF) job selection dispatching rule outperforms all other applied job selection dispatching rules for the same problem in all four FMS layouts. The smallest remaining processing time first (SRPTF) and smallest slack time first (SSTF) job selection dispatching rule observed to perform moderately and the greatest waiting time in queue first (GWTQF) job selection dispatching rule found to be the least performer among all dispatching rules for an overall production rate of the FMS. In the investigations, it was also observed that the performance of FMS is also governed by other factors such as the number of AGVs in the FMS and AGV cruising speed in the FMS layout. Hence it can be concluded that the overall production rate and WC utilization in FMS are dependent on the performance of material handling operations performed by multi-load AGVs in the FMS layouts. Therefore critical factors which may affect the performance of multi-load AGVs such as selection of appropriate dispatching rules, AGV speed and number of AGVs must be investigated and they should be appropriately selected for designing and implementation of efficient AGV based material handling system. Future research work may include more detailed investigations and analysis of other control issues which may affect performance and production rate of the FMS. The control issues may include but not limited to the part type mix, detailed analysis of a number of loading and unloading points and type of configuration i.e. tandem or SFT when served by bidirectional multi-load AGVs operating under some different set of dispatching rules in the FMS.

\section{References}

Azimi, P., Haleh, H., \& Alidoost, M. (2010). The selection of the best control rule for a multiple load AGV system using simulation and fuzzy MADM in a flexible manufacturing system. Modelling and Simulation in Engineering, $2010,7$.

Bilge, U., \& Tanchoco, J. M. (1997). AGV systems with multi-load carriers: basic issues and potential benefits. Journal of Manufacturing Systems, 16(3), 159.

Bottani, E., Centobelli, P., Cerchione, R., Gaudio, L., \& Murino, T. (2017). Solving work center loading problem of flexible manufacturing systems using a modified discrete firefly algorithm. International Journal of Industrial Engineering Computations, 8(3), 363-372. 
Chawla, V., Chanda, A., \& Angra, S. (2018 a). Scheduling of multi-load AGVs in FMS by modified memetic particle swarm optimization algorithm. Journal of Project Management, 3(1), 39-54.

Chawla, V., Chanda, A., \& Angra, S. (2018 b). Automatic guided vehicles fleet size optimization for flexible manufacturing system by grey wolf optimization algorithm. Management Science Letters, 8(2), 79-90.

Chawla, V.K., Chanda, A., \& Angra, S. (2018 c). The sustainable project management: A review and future possibilities. Journal of Project Management, DOI: 10.5267/j.jpm.2018.2.001

Chawla, V.K., Chanda, A., \& Angra, S. (2018 d). A Clonal Selection Algorithm for Minimizing Distance Travel \& Back Tracking of Automatic Guided Vehicles in Flexible Manufacturing System. Journal of The Institution of Engineers (India): Series C, DOI: 10.1007/s40032-018-0447-5.

Cheng, T. C. E. (1987). A simulation study of automated guided vehicle dispatching. Robotics and Computer-Integrated Manufacturing, 3(3), 335-338.

De Guzman, M. C., Prabhu, N., \& Tanchoco, J. M. A. (1997). Complexity of the AGV shortest path and single-loop guide path layout problems. International Journal of Production Research, 35(8), 2083-2092.

Hammond, G. (1986). AGVS at work: automated guided vehicle systems. Springer Verlag.

Hao, G., Shang, J. S., \& Vargas, L. G. (1996). A neural network model for the free-ranging AGV route-planning problem. Journal of Intelligent Manufacturing, 7(3), 217-227.

Ho, Y. C., \& Shaw, H. C. (2000). The performance of multiple-load AGV systems under different guide path configurations and vehicle control strategies. International Journal of Manufacturing Technology and Management, 1(2-3), $218-231$.

Ho, Y. C., \& Liu, H. C. (2009). The performance of load-selection rules and pickup-dispatching rules for multiple-load AGVs. Journal of Manufacturing Systems, 28(1), 1-10.

Ho, Y. C., Liu, H. C., \& Yih, Y. (2012). A multiple-attribute method for concurrently solving the pickup-dispatching problem and the load-selection problem of multiple-load AGVs. Journal of Manufacturing Systems, 31(3), 288-300.

Kelton, W. D. (2002). Simulation with ARENA. McGraw-hill.

Kim, C. W., \& Tanchoco, J. M. (1991). Conflict-free shortest-time bidirectional AGV routeing. The International Journal of Production Research, 29(12), 2377-2391.

Kumar, V. Chawla, Chanda, A., \& Angra, S. (2018). Evaluation of Hybrid Dispatching Rules for Simultaneous Scheduling of AGVs in FMS. 1st International Conference on New Frontiers in Engineering, Science \& Technology, New Delhi, India, January 8-12, 2018, 105-112

Langevin, A., Lauzon, D., \& Riopel, D. (1996). Dispatching, routing, and scheduling of two automated guided vehicles in a flexible manufacturing system. International Journal of Flexible Manufacturing Systems, 8(3), 247-262.

Lee, J., Tangjarukij, M., \& Zhu, Z. (1996). Load selection of automated guided vehicles in flexible manufacturing systems. International Journal of Production Research, 34(12), 3383-3400.

Lin, L., Shinn, S. W., Gen, M., \& Hwang, H. (2006). Network model and effective evolutionary approach for AGV dispatching in manufacturing system. Journal of Intelligent Manufacturing, 17(4), 465-477.

Moghadam, B. F., Sadjadi, S. J., \& Seyedhosseini, S. M. (2010). An empirical analysis on robust vehicle routing problem: a case study on drug industry. International Journal of Logistics Systems and Management, 7(4), 507-518.

Moghaddam, B. F., Ruiz, R., \& Sadjadi, S. J. (2012). Vehicle routing problem with uncertain demands: An advanced particle swarm algorithm. Computers \& Industrial Engineering, 62(1), 306-317.

Rajotia, S., Shanker, K., \& Batra, J. L. (1998). A semi-dynamic time window constrained routeing strategy in an AGV system. International Journal of Production Research, 36(1), 35-50.

Sadrabadi, M. R., \& Sadjadi, S. J. (2009). A new approach to solve multiple objective programming problems. International Journal of Industrial Engineering \& Production Research, 20(1), 41-51.

Singh, R., \& Khan, B. (2016). Meta-hierarchical-heuristic-mathematical-model of loading problems in flexible manufacturing system for development of an intelligent approach. International Journal of Industrial Engineering Computations, 7(2), 177-190.

Taghaboni-Dutta, F., \& Tanchoco, J. M. A. (1995). Comparison of dynamic routeing techniques for automated guided vehicle system. International Journal of Production Research, 33(10), 2653-2669.

Tanchoco, J. M. A. and Co, C. G. (1994), Real-Time Control Strategies for Multiple-Load AGVs, Material Flow Systems in Manufacturing, edited by J. M. A. Tanchoco, (ed), Chapman \& Hall, London.

Um, I., Cheon, H., \& Lee, H. (2009). The simulation design and analysis of a flexible manufacturing system with automated guided vehicle system. Journal of Manufacturing Systems, 28(4), 115-122.

Wang, Y. C., Chen, T., Chiang, H., \& Pan, H. C. (2016). A simulation analysis of part launching and order collection decisions for a flexible manufacturing system. Simulation Modelling Practice and Theory, 69, 80-91.

Yim, D. S., \& Linnt, R. J. (1993). Push and pull rules for dispatching automated guided vehicles in a flexible manufacturing system. The International Journal of Production Research, 31(1), 43-57.

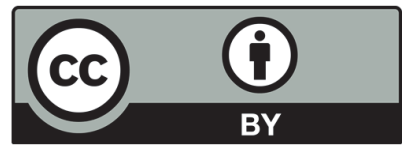

(C) 2018 by the authors; licensee Growing Science, Canada. This is an open access article distributed under the terms and conditions of the Creative Commons Attribution (CC-BY) license (http://creativecommons.org/licenses/by/4.0/). 